\title{
Pore Narrowing and Formation of Ultrathin Yttria-Stabilized Zirconia Layers in Ceramic Membranes by Chemical Vapor Deposition/Electrochemical Vapor Deposition
}

\author{
Guo-zhong Cao, ${ }^{\star}$ Hendrik W. Brinkman, Joan Meijerink, \\ Karel J. de Vries, and Anthonie J. Burggraaf
}

Laboratory of Inorganic Chemistry, Materials Science and Catalysis, Department of Chemical Engineering, University of 'Twente, 7500 AE Enschede, The Netherlands

\begin{abstract}
Chemical vapor deposition (CVD) and electrochemical vapor deposition (EVD) have been applied to deposit yttriastabilized-zirconia (YSZ) on porous ceramic media. The experimental results indicate that the location of YSZ deposition can be varied from the surface of the substrates to the inside of the substrates by changing the CVD/EVD experimental conditions, i.e., the concentration ratio of the reactant vapors. The deposition width is strongly dependent on the deposition temperature used. The deposition of YSZ inside the pores resulted in pore narrowing and eventually pore closure, which was measured by using permporometry. However, deposition of YSZ on top of porous ceramic substrates (outside the pores) did not result in a reduction of the average pore size. Ultrathin, dense YSZ layers on porous ceramic substrates can be obtained by suppressing the EVD layer growth process after pore closure.
\end{abstract}

\section{Introduction}

A MONG the ceramic ionic conducting materials, yttria-stabilized zirconia (YSZ) with a fluorite type of structure is one of the most attractive candidates for applications such as electrolytes in solid oxide fuel cells (SOFC) and semipermeable membranes in gas separation. In order to optimize the efficiency of the applications, it is very important to prepare very thin or ultrathin, dense YSZ layers. Decreasing the thickness of the YSZ layer lowers the ohmic polarization loss for SOFC applications and maximizes the oxygen permeation flux, assuming a sufficiently large surface exchange rate. If conventional methods are used, it is very difficult to prepare a very thin, dense YSZ layer (with thickness less than $1 \mu \mathrm{m}$ ).

Chemical vapor deposition (CVD) and electrochemical vapor deposition (EVD) techniques have demonstrated the possibilities for the preparation of very thin, dense, oxygen semipermeable YSZ layers on porous ceramic substrates. ${ }^{1-5}$ In the CVD stage the metal reactants (metal chloride vapors) are delivered to one side of a porous substrate, which separates the CVD/EVD reactor chamber into two compartments, while the oxygen reactant (water vapor and oxygen gas) is supplied to the other side. The reactants counterdiffuse and react to form and deposit solid YSZ inside the pores, causing pore narrowing and eventually pore plugging. After pore closure the CVD process stops while the EVD process begins; i.e., the water vapor and oxygen gas diffuse through the porous substrate to the YSZ

T. M. Besmann-contributing editor

\footnotetext{
Manuscript No. 194916. Received January 25, 1993; approved April 20, 1993. Supported by the Dutch Ministry of Economic Affairs (Research Project "ECVD Synthesis and Properties of Porous Composite Systems," IOP Technical Ceramics Synthesis and Properties of Porous Com
No. 87.A045, 89.A045, and 90.A345)

"Member, American Ceramic Society.
}

plug and are reduced to oxygen ions at the oxygen/plug interface. The oxygen ions diffuse through the YSZ film and then react with the metal chlorides to form YSZ at the metal/plug interface, resulting in growth of a dense YSZ layer. Previous work in the literature has been focused mainly on kinetic studies of the growth process of the thin dense YSZ layer with both theoretical analysis and experimental studies. ${ }^{1-7}$ However, a good understanding of the CVD process is more essential for the preparation of very thin or ultrathin, dense, oxygen semipermeable layers on porous ceramic substrates, because in order to obtain an ultrathin YSZ layer shortly after the pore closure caused by CVD the deposition process should stop, i.e., the EVD YSZ layer growth process should be suppressed.

CVD has been used for the preparation and modification of porous ceramic membranes. ${ }^{8,9}$ By depositing solid oxide(s) inside the pores, the pore size of the porous ceramic membranes is expected to be reduced. Thus ceramic membranes with pore sizes in the nano- and/or subnano-scale range can possibly be prepared and modified for applications such as gas separations. It is very important to have a very narrow deposition broadness for obtaining a very thin dense layer and for achieving maximum application efficiency (a minimum intrapore diffusion resistance). However, for some catalytic applications a broad deposition zone of CVD oxide(s) is preferred. Lin et al ${ }^{8.10}$ have reported a theoretical analysis by using mathematical modeling and also experimental results on the preparation and modification of ceramic membranes by CVD. By using a method of gas permeation measurement they have found that the porosity of the ceramic substrates (more precisely, the gas diffusional flux through the substrates) is reduced but the average pore size is not reduced by depositing solid oxide inside the pores. ${ }^{8}$ However, the gas permeation method only provides information on gas diffusional resistance of the porous membranes, and therefore the estimation of the change of average pore size is not straightforward and yields correct values only under specific boundary conditions. Heretofore, no one has reported a change of pore size distribution in porous ceramic substrates due to deposition of solid oxide(s) inside the pores concerning preparation and modification of porous membranes. The present paper is thus focused mainly on the CVD stage by studying the deposition profile and pore narrowing and plugging caused by depositing YSZ in porous ceramic substrates.

In the present work, permporometry, a relatively new technique, is introduced for examining the change in the pore size (distribution) of porous ceramic substrates due to the deposition of solid oxides by using CVD technique. This method is based on controlled blocking of the pores by capillary condensation of a vapor phase (cyclohexane) and the simultaneous measurement of the gas diffusional flux (oxygen) through the remaining open pores. The principle of the method has been described in detail in Refs. 11-13. It is demonstrated in the present work that this method is unique for the determination of the 
change of pore size (distribution) in porous substrates caused by depositing YSZ.

\section{Experimental Procedure}

\section{(l) CVD/EVD on Porous Ceramic Substrates}

The chemicals used in the CVD/EVD experiments were $\mathrm{ZrCl}_{4}$ (99.9\%, 200 mesh, CERAC, Milwaukee, WI), $\mathrm{YCl}_{3}$ (99.9\%, 60 mesh, CERAC), $\mathrm{H}_{2} \mathrm{O}$ (doubly distilled), Ar gas (99.999\%, UHP 5.0, Nieuw Vennep, Netherlands), and air (technical, Hoekloos, Schiedam, Netherlands). Two types of substrates (disks: $12 \mathrm{~mm}$ in diameter and $2 \mathrm{~mm}$ in thickness) were used, namely type $A$ and type $B$. The type A substrate consisted of a single plate of $\alpha$-alumina with a porosity of $43 \%$ and a mean pore diameter of $0.16 \mu \mathrm{m}$, which were determined by using mercury porosimetry (Series 200, Carlo-Erba, Rodana, Italy). The type B substrate was formed by adding a layer of La-doped $\gamma$-alumina ceramic membrane on top of the $\alpha$-alumina substrate (type A), in which the $\alpha$-alumina acted as a supporting layer. The La-doped $\gamma$-alumina layer was made by using the sol-gel technique and was dip-coated ( 2 times) onto the $\alpha$-alumina substrate. The La-doped $(\gamma+\alpha)$-alumina membrane was first dried slowly at a controlled moisture condition, calcined at $450^{\circ} \mathrm{C}$ for $3 \mathrm{~h}$, and then fired at $1100^{\circ} \mathrm{C}$ in air for $30 \mathrm{~h}$ so as to obtain a stabilized pore size and porosity. In order to estimate the porosity and pore size of the supported Ladoped $\gamma$-alumina membrane, a La-doped $\gamma$-alumina membrane without an $\alpha$-alumina supporting layer was prepared, and its porosity (about $50 \%$ ) and pore size $(20 \mathrm{~nm}$ in diameter) were measured by using the nitrogen adsorption-desorption technique (at liquid-nitrogen temperature, $77 \mathrm{~K}$, Asap 2400, Micromeritics, Norcross, GA). It was assumed that the porosity and pore size of the supported La-doped $\gamma$-alumina membrane were close to those of the unsupported one. The pore size distribution of the supported La-doped $\gamma$-alumina membrane was also measured by means of permporometry (details are given later in this paper) and the mean pore diameter was found to be about $18 \mathrm{~nm}$, similar to that of the unsupported one. The thickness of the La-doped $\gamma$-alumina top layer was approximately $5 \mu \mathrm{m}$ according to SEM observation. The details of the preparation and characterization of the La-doped $(\gamma+\alpha)$-alumina membrane have been presented previously. ${ }^{14}$

The CVD/EVD experiments were performed in an apparatus which consisted of three sections: a reactor (as sketched in Fig. 1), a vacuum-control section, and a reactant-delivery section. The CVD/EVD experimental conditions used are given in Table I unless otherwise specified. In this study the experimental conditions were different from those used previously in our laboratory. ${ }^{2.8}$ The changes included a decrease of all gas fluxes (in both chloride and water chambers) to ensure that the carrier gas was saturated with the reactant vapors. Such a change was expected to result in an increase of the chloride concentration as well as the chloride/water concentration ratio (compared with the experimental conditions used pre-viously ${ }^{2.8}$ ), and details will be discussed later in Section III. Also a lower deposition temperature was used so as to minimize the YSZ layer growth in the EVD stage. A porous substrate disk (either type A or B) was sealed to a dense alumina tube inside the reactor by using "Autostic" cement (CF8, Carlton Brown \& Partners Ltd., Sheffield, U.K.). For the type B substrate the disk was put in such a way that the La-doped $\gamma$-alumina top layer always faced the metal chloride chamber. A mixture of the sublimated chloride vapors, diluted and carried by Ar gas, flowed and diffused into the pores of the substrate at one side and in the meantime a mixture of water vapor and air was led into the pores of the substrate at the other side. When the experimental conditions were chosen appropriately, inside the pores the reactants counterdiffused and reacted to form a solid, yttria-stabilized zirconia (YSZ). The YSZ deposited on the inner surface of the pores and this caused

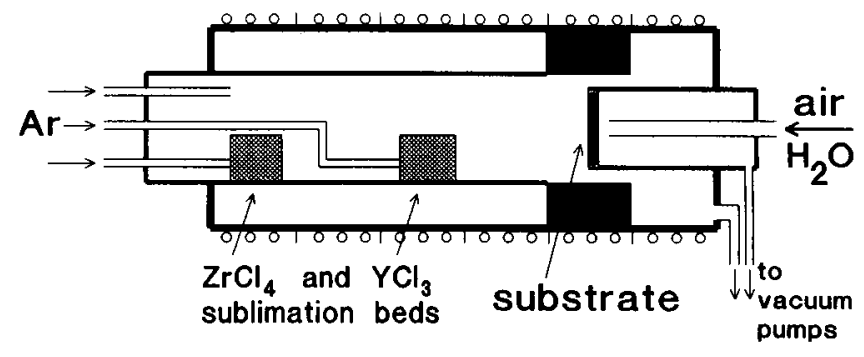

Fig. 1. Schematic diagram of the CVD/EVD reactor.

pore narrowing and eventually pore plugging. The subsequent EVD process resulted in growing of an YSZ dense layer on the porous substrates. Under different experimental conditions an YSZ layer can grow (outside the pore system) on top of the membrane. This will be discussed later.

\section{(2) Characterization of Deposition Profile}

The chemical composition and crystal structure of yttriastabilized zirconia deposited on the porous ceramics were analyzed by means of XRF (PW1480, Philips, Eindhoven, Netherlands) and XRD (PW1710, Philips, $\mathrm{Cu} K \alpha$ ), respectively. The study of the deposition profile of YSZ in the porous ceramic substrates was conducted mainly by means of scanning Auger microscopy (SAM) (Philips, PHI 600) and scanning electron microscopy (SEM) (JSM-35CF, Jeol, Tokyo, Japan) with energy dispersion spectroscopy (EDS) (Kevex, Foster City, CA). The substrates with YSZ deposition were put into liquid nitrogen and then broken into pieces in air so as to obtain a smooth cross-section surface with YSZ deposition intact. Such a fresh cross-section surface was then subjected to SEM/EDS (with carbon coating) and SAM analyses. For SEM/EDS analyses (of both linescan and point analyses), the following conditions were used: accelerating voltage, $25 \mathrm{kV}$; electron beam current, $8 \times 10^{-6} \mathrm{~A}$; analysis time, $60 \mathrm{~s} /$ line for linescan analysis and $30 \mathrm{~s} /$ point for point analysis; and depth resolution, about $1 \mu \mathrm{m}$. The following experimental conditions were used in the SAM analyses: primary beam energy, $6 \mathrm{keV}$; primary beam current, $0.75 \mathrm{nA} ; 160$ points/line; analysis time per point, 11,5 , and $1 \mathrm{~s}$ for the $\mathrm{Zr}-L M M, \mathrm{Al}-L M M$, and $\mathrm{O}-K L L$ Auger transitions, respectively; energy resolution of the cylindrical mirror, $1.2 \%$. Under these conditions the detection limit for $\mathrm{Zr}$ was $<5 \%$ (atomic concentration) and the lateral resolution, defined as the distance between two points on the Auger linescan corresponding to $20 \%$ and $80 \%$ of the maximum Auger signals, was found to be about $300 \mathrm{~nm}$. The sample was tilted at about $60^{\circ}$ in order to avoid electrostatic charging.

\section{(3) Permporometry}

The change of pore size (distribution) in porous substrates caused by the deposition of YSZ was determined by using permporometry. A schematic diagram of the experimental setup of permporometry is given in Fig. 2. This apparatus consists of four parts. The first part is the gas flow system, including the condensable vapor generators, spiral coolers,

Table I. CVD/EVD Experimental Conditions

\begin{tabular}{ll}
\hline Substrate temperature & $800^{\circ} \mathrm{C}$ \\
$\mathrm{ZrCl}_{4}$ sublimation bed temperature & $160^{\circ} \mathrm{C}$ \\
$\mathrm{YCl}_{3}$ sublimation bed temperature & $640^{\circ} \mathrm{C}$ \\
$\mathrm{YCl}_{3} / \mathrm{ZrCl}_{4}$ ratio in vapor & $3 / 10$ \\
$\mathrm{Reactor}$ pressure & $2 \mathrm{mbar}(200 \mathrm{~Pa})$ \\
$\mathrm{Ar}$ carrier gas stream through $\mathrm{ZrCl}_{4}$ bed & $3 \mathrm{~mL}(\mathrm{STP}) / \mathrm{min}$ \\
$\mathrm{Ar}$ carrier gas stream through $\mathrm{YCl}_{3}$ bed & $1.5 \mathrm{~mL}(\mathrm{STP}) / \mathrm{min}$ \\
Total Ar gas stream on chloride $\mathrm{side}$ & $5.5 \mathrm{~mL}(\mathrm{STP}) / \mathrm{min}$ \\
Air stream through $\mathrm{H}_{2} \mathrm{O}$ sparger & $0.7 \mathrm{~mL}(\mathrm{STP}) / \mathrm{min}$ \\
Water sparger temperature & $40^{\circ} \mathrm{C}$ \\
Total pressure in water sparger & $150 \mathrm{mbar}(15 \mathrm{kPa})$ \\
\hline
\end{tabular}


mass flow controllers, differential pressure transducer, and gas mixers. The second part is the diffusion cell, where the capillary condensation inside pores and the gas diffusion through the remaining open pores take place. The third part is the gas chromatograph and a data recorder. The fourth part is the temperature-controlling system, including the water bath, etc.

A mixture of cyclohexane vapor, acting as a condensable gas, and nitrogen gas was flushed at the membrane side of the specimen, where the YSZ deposition occurred. The other side (supporting layer) of the specimen was flushed with a mixture of cyclohexane vapor, nitrogen, and oxygen gases. Note that, theoretically, the way the specimens were placed in the diffusion cell should have had no influence on the experimental results. The total (absolute) pressure inside the diffusion cell was about 1 bar and the gas flux along each side of the specimen was about 50 (STP) $\mathrm{mL} / \mathrm{min}$. The condensable gas can be any vapor, provided that it has a reasonable vapor pressure, a high evaporation rate, and is inert to the specimens to be characterized. The condensable gas should also have a good wettability and consist of small, spherical molecules. $\mathrm{CCl}_{4}$ should be an ideal candidate, ${ }^{15}$ but it is also a very poisonous gas, and thus it was not used in our experiments. According to Ref. 11, cyclohexane is a good candidate and hence was chosen for our experiments. Nitrogen was used as a carrier gas for the condensable gas (and formed the balance to 1 bar total pressure) while oxygen gas was added for the determination of gas diffusion through the substrates (by using a gas chromatograph). From the permporometry setup one can see that the oxygen partial pressure $\left(P_{\mathrm{O}_{2}}\right.$, on the high oxygen pressure side) varies with $1-P_{\mathrm{r}}\left(P_{\mathrm{r}}\right.$ being the relative vapor pressure of cyclohexane). Gas diffusion through the pores of the porous ceramic substrates used in this study was in the region of Knudsen diffusion (low pressure gas diffusing through small pores). There was no overall pressure gradient across the substrates; the oxygen gas transport through the substrates was due to the oxygen gas concentration gradient (or the oxygen differential partial pressure) across the specimens. Thus the oxygen gas transported through the substrates was assumed to be proportional to the oxygen differential partial pressure across the substrates in the pressure range measured (from 0 to $1 \mathrm{~atm}$ ). The oxygen diffusional flux through the pores of the porous ceramic substrates was corrected with the oxygen differential partial pressure (driving force), which is defined as the oxygen permeation (the oxygen flux per unit of driving force, i.e., the pressure drop). Note that the oxygen permeation presented in this paper is in fact the oxygen permeation through the specimens consisting of both the toplayer membrane and the supporting layer. The permporometry experiments reported in the present paper were all conducted using a desorption process, because a shorter time was needed to reach equilibrium. The equilibrium time was about $20-40$ min for desorption measurements and much longer for adsorption ones. The temperature of the diffusion cell was kept at $15^{\circ} \mathrm{C}$.

At the beginning of the measurements both sides of the substrate in the diffusion cell were flushed with the (mixed) gases saturated with cyclohexane vapor. All pores in the substrate were then filled with liquid cyclohexane because of capillary condensation and no gas diffusion through the substrate was possible. When the relative vapor pressure of cyclohexane was subsequently reduced, pores with Kelvin radii equal to or larger than a corresponding size (determined by the Kelvin equation ${ }^{16}$ ) were opened and available for gas diffusion. By stepwise decrease of the vapor pressure, the oxygen diffusional flux through the substrate was measured, from which the size distribution of active pores was calculated.

In the permporometry study the size distribution of "active" pores in porous ceramic substrates before and after CVD experiments was measured. Active pores are those effective for gas diffusion, while dead-end pores, also called "passive" pores, have no contribution for gas diffusion. Details of the technique, the measurement experiments, and the calculation of the pore size distribution are presented elsewhere. ${ }^{17}$

\section{Results and Discussion}

\section{(1) CVD of YSZ on Porous Ceramic Substrates}

$\mathrm{XRD}$ analyses show that the deposition on both type $\mathrm{A}$ and type B substrates was mostly yttria-stabilized zirconia (YSZ), solid solutions with a fluorite-type structure. However, small amounts of tetragonal and monoclinic zirconia phases (less than $15 \%$ of the total amount of yttria-zirconia solid solutions, estimated according to XRD analysis) were also found in some experiments. $\mathrm{XRF}$ was used to determine the $\mathrm{Zr}$ and $\mathrm{Y}$ concentration (ratio) in the yttria-zirconia deposition in porous ceramics (both type $A$ and $B$ substrates) and the experimental results indicated a composition of $\mathrm{Y}_{0.17} \mathrm{Zr}_{0.82} \mathrm{O}_{1.91}$ for the deposition on both type $\mathrm{A}$ and type $\mathrm{B}$ substrates.

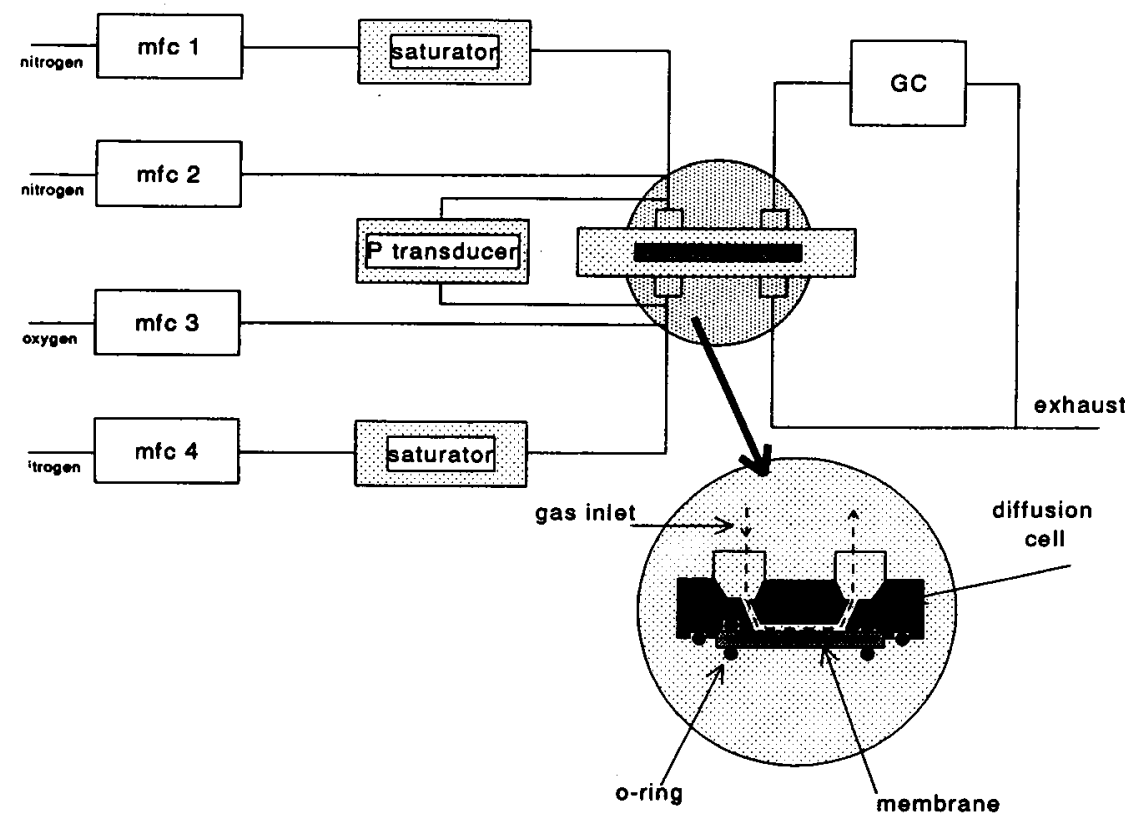

Fig. 2. Schematic diagram of the permporometry setup. 


\section{(2) Deposition Profile}

The SEM/EDS and SAM analyses showed that when the CVD/EVD experiments were performed by using the experimental conditions given in Table I, the deposition of YSZ on both type A and type B substrates occurred inside the pores very close to the surface toward the chloride chamber. Figure 3 shows the deposition profile of YSZ, determined by means of an EDS linescan, in the type A substrate with 20-min deposition of $Y S Z$ at $800^{\circ} \mathrm{C}$. The deposition zone was about 5 $\mu \mathrm{m}$ wide with the maximum deposition close to the surface toward the metal chloride chamber. In the present paper the deposition zone (width) is defined as a region where the YSZ deposition content is not less than $10 \%$ of the maximum YSZ deposition observed in the specimen. It is not necessary for the deposition width to be the thickness of the dense plug within the pores at pore closure time, nor will the pore diameter be constant within this region (deposition zone). Figure 3 also shows that a very small amount of YSZ was found deep inside the substrate. This may be due to pre- and postdeposition. In the CVD/EVD reactor the chloride sublimation beds were inserted into the reactor chamber about $0.5 \mathrm{~h}$ before the CVD/EVD experiments started, and left inside after the CVD/EVD experiments ended until the reactor cooled down. In this way the evaporation of metal chlorides took place before the CVD/EVD experiments and the metal chloride vapors diffused into the substrates. After the CVD/EVD experiments the supply of water vapor and oxygen gas was cut off immediately. However, the evaporation of metal chlorides could not be stopped at once and thus the metal chloride vapors could still diffuse through the remaining open pores and penetrate inside the substrates. When the substrates were taken out after the CVD/EVD experiments, the metal chlorides were partly oxidized as a result of contact with the air (oxygen gas and/or water vapor). The existence of chlorides inside the substrates was also observed by means of EDS. It is clear that the depth of yttria-zirconia penetration is dependent on the experimental procedures.

The width of the YSZ deposition varies with the concentration ratio of the reactants and the deposition temperature. When a lower deposition temperature is used, a narrower deposition width is obtained. An illustrative example is given in Fig. 4, which shows the effect of the deposition temperature on the deposition width in the type A substrate, determined by means of EDS point analysis. The $X$-axis in Fig. 4 is the (cross-section) distance from the substrate surface facing the chloride chamber and the units of the $Y$-axis are arbitrary. When the CVD experiment is conducted at a temperature of $1000^{\circ} \mathrm{C}$, the width of the $\mathrm{YSZ}$ deposition is

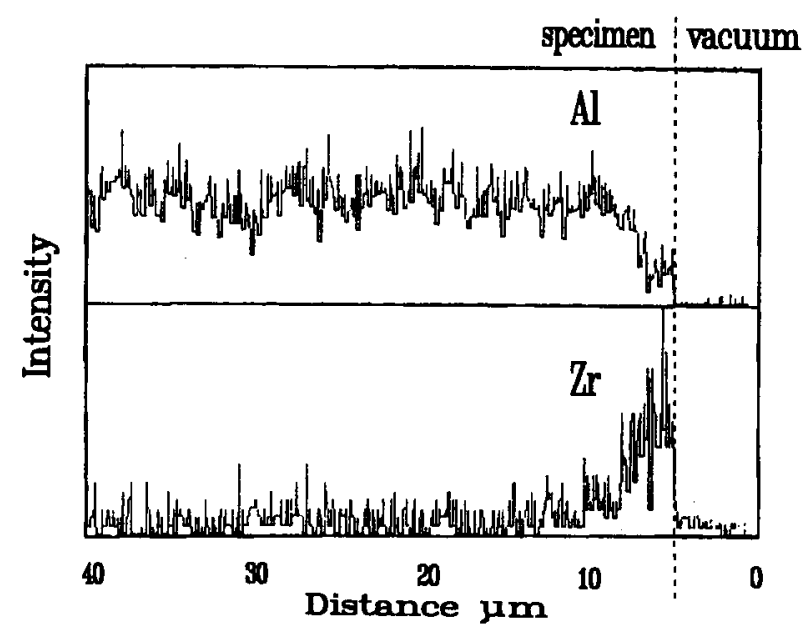

Fig. 3. Deposition profile of YSZ in the type A substrate with 20-min CVD (experimental conditions given in Table I) (determined by EDS linescan analysis). approximately $19 \mu \mathrm{m}$, about 4 times broader than that at $800^{\circ} \mathrm{C}$. This result is ascribed to the Langmuir-Hinshelwood reaction mechanism, in which the reaction rate decreases with increasing temperature under certain boundary conditions. ${ }^{10.18,19}$ Also the diffusivity of the reactant vapors increases with the temperature. The deposition width increases with the ratio of the diffusivity of the reactant vapors to the reaction rate constant according to the theoretical analysis and mathematical modeling, details of which are presented elsewhere. ${ }^{10,18,19}$

The deposition profile of YSZ in the type B substrate is very similar to that in the type A substrate. The width of the YSZ deposition in the type $B$ substrate at $800^{\circ} \mathrm{C}$ was about $5 \mu \mathrm{m}$, similar to that in the type A substrate. The deposition of YSZ normally occurred at the La-doped $\gamma$-alumina top layer, which was always on the side toward the metal chloride chamber during the CVD experiments, and no or very little YSZ deposition was found to penetrate into the supporting $\alpha$-alumina layer.

The deposition location could be varied by changing the concentration ratio of the reactants according to the mathematical modeling work reported by Lin et al. ${ }^{10}$ The theoretical prediction was confirmed by our experimental results. Increasing the water vapor concentration and/or decreasing the metal chloride concentration resulted in a shift of the YSZ deposition toward the surface near the metal chloride chamber. When the concentration of metal chloride vapors was reduced about 5 times while the water vapor concentration remained unchanged, the YSZ deposition was shifted outside the pores to the surface of the substrate facing the metal chloride chamber. This was true for both type $A$ and type $B$ substrates. Figure 5 gives an example of the profile of such a deposition. The deposition was conducted on the type $B$ substrate for 20 min with (5 times) reduced concentration of metal chloride vapors by changing gas fluxes in the chloride chamber in the way described below. The carrier gas through the (both $\mathrm{ZrCl}_{4}$ and $\mathrm{YCl}_{3}$ ) sublimation beds remained unchanged, while the dilution gas, which flowed through a separate pipe (details seen in the experimental setup, Fig. 1), was increased accordingly. The sublimation temperatures of metal chlorides and other experimental conditions remained unchanged, as shown in Table I. The deposition profile (topocorrected results), given in Fig. 5, was determined by using SAM line scanning analysis. In this figure the surface of the substrate was on the right side, so as to avoid electrostatic charging. In Fig. 5 the region from 9 to $10 \mu \mathrm{m}$ was in fact under vacuum. Most of the YSZ deposition was observed in the region from 8.3 to $9 \mu \mathrm{m}$, and aluminum was found only in the region from 0 to $7 \mu \mathrm{m}$. This observation indicated a very narrow deposition of YSZ (less than $1 \mu \mathrm{m}$ ) on top of the substrate (not inside the substrate). A very small amount of zirconium in the region from 0 to $8 \mu \mathrm{m}$ implied a little penetration of YSZ deposition inside the substrate. This deposition profile also showed a sharp decrease of oxygen concentration in the region

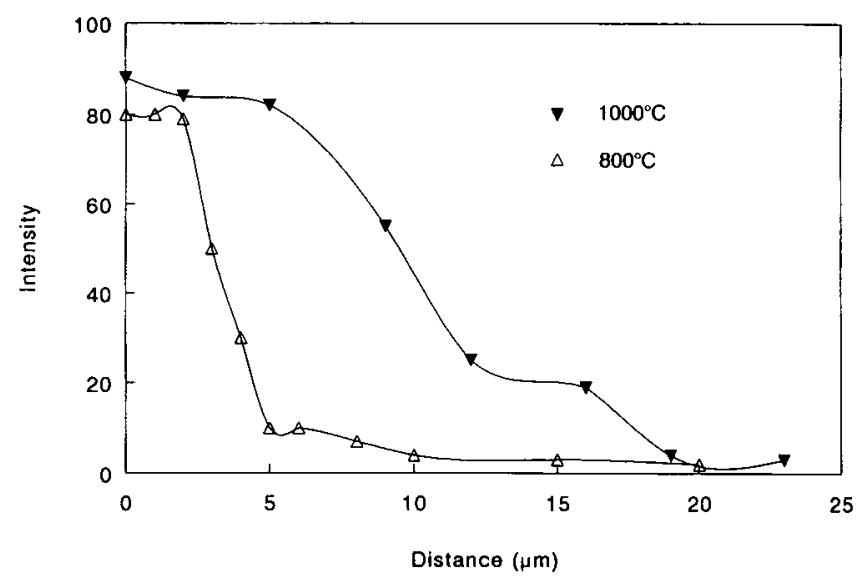

Fig. 4. Effect of the deposition temperature on the deposition width of YSZ in the type A substrate (determined by EDS point analysis). 
from 7.7 to $8.3 \mu \mathrm{m}$. The aluminum content also decreased to zero at about $7.7 \mu \mathrm{m}$, while a large amount of zirconium was only seen starting approximately at $8.3 \mu \mathrm{m}$. This deposition gap of the metal elements and the decrease of the oxygen concentration implied that a porous layer existed between the YSZ layer and the La-doped $\gamma$-alumina layer. This porous layer was also observed by means of SEM observation. Similar results were reported previously in Ref. 1 as well. Such a deposition profile can probably be explained as follows. In CVD/EVD experiments, when the concentration of metal chloride vapors in the chloride chamber is lowered (by changing either the gas fluxes or the sublimation temperatures) and thus the amount of chloride vapors diffused into the pores of the substrate is smaller, while the concentration of water vapor and oxygen gas remains the same in the water chamber, a deficient amount of metal chloride vapors and/or an excess amount of water vapor and oxygen gas will drive (shift) the deposition toward the metal chloride chamber as predicted. ${ }^{10}$ In an extreme case, water vapor and oxygen gas will diffuse through the porous ceramic substrate and meet the metal chloride vapors outside the pores (instead of inside the pores), and consequently the reaction and deposition take place outside the pores on top of the substrate facing the chloride chamber. Since such a chemical reaction is most probably a homogeneous one, a porous deposition would be expected.

The work reported previously by Lin et $a l .^{2.8}$ was performed by using ( 5 times) higher gas fluxes (in both chloride and water chambers) than those (given in Table I) used in the present study. By using high gas fluxes in the CVD experiments it is often found that deposition occurs on top of the substrates, in particular when the type B substrates are used. The gas through the water sparger is expected to be easily saturated with water vapor. However, a gas flux with a high rate passing above the metal chloride powders (sublimation beds) is probably difficult to saturate. When the evaporation of the metal chlorides is not fast enough to match the gas flow rate, the concentration of the metal chloride vapors in the chloride chamber would be lower than those which are desired to deposit YSZ inside the pores and are estimated from the vapor pressures of the metal chlorides. Consequently a deficient amount of metal chloride vapors supplied would result in a deposition (outside the pores) on top of the substrates as discussed above.

The location of the YSZ deposition could be shifted toward the inside of the substrates by increasing the concentration of metal chlorides and/or decreasing the concentration of oxygen reactant(s). The YSZ deposition inside the substrates (down 25 $\mu \mathrm{m}$ from the surface, on the type A substrates) was also observed by means of SEM/EDS and SAM. Such a deposition could be useful for chemical vapor infiltration (CVI) study. More detailed work is beyond the scope of this paper.

\section{(3) Pore Size Reduction}

Modified CVD in porous ceramic substrates is in fact a process of combined counterdiffusion and reaction of reactant vapors inside the pores. Thus the deposition of YSZ occurs only in those pores effective for gas diffusion; i.e., the reactant vapors diffuse mainly through those active pores and/or the deposition of YSZ takes place inside those active pores. So in the present study dead-end pores are not taken into consideration. Another reason for taking only active pores into account is that the permporometry measures only active pores. Note also that the pores in both type A and type B substrates are thermally stable; i.e., during the CVD/EVD experiments (at $800^{\circ} \mathrm{C}$ ) no sintering and no pore growth occur.

The experimental results indicate that the deposition of YSZ on both type A and type B porous ceramic substrates does not always result in a reduction of pore size. Whether a reduction of the pore size (distribution) occurs or not is dependent on the deposition location (deposition profile). When the YSZ deposition occurs inside the pores (whether near the surface or not), the pore size decreases. However, the deposition of YSZ on the top or the surface (i.e., outside the pores) of the porous ceramic substrates will not result in a reduction of pore size. Figure 6 gives the pore size distribution in the type A substrate after 20 -min deposition of $Y S Z$ and the average pore radius is calculated to be approximately $20 \mathrm{~nm}$ (details of the calculation are reported in Ref. 17). This figure shows also the accumulative oxygen diffusional flux through the substrate as a function of pore radii. The deposition was conducted by using the experimental conditions given in Table I and the deposition of YSZ was located inside the pores as shown previously in Fig. 3. Such a deposition resulted in a reduction of the pore size, from $80 \mathrm{~nm}$ (before CVD, determined by using mercury porosimetry) to $20 \mathrm{~nm}$ in radius (determined by permporometry). The oxygen permeation through the substrate (at $P_{\mathrm{r}}=0$ ) decreased from $41 \times 10^{-8}$ to $39 \times 10^{-8}$ $\mathrm{mol} /\left(\mathrm{m}^{2} \cdot \mathrm{s} \cdot \mathrm{Pa}\right)\left(\right.$ measured at $\left.15^{\circ} \mathrm{C}\right)$. This small decrease of the oxygen permeation after deposition was probably due to the narrow deposition width (approximately $5 \mu \mathrm{m}$ ) in comparison with the thickness, $2 \mathrm{~mm}$, of the substrate. The pore narrowing in this small region probably contributed a little to the total resistance to oxygen permeation through the substrate.

A reduction of the pore size was also observed in the case of the type B substrate by depositing YSZ inside the pores. Figure

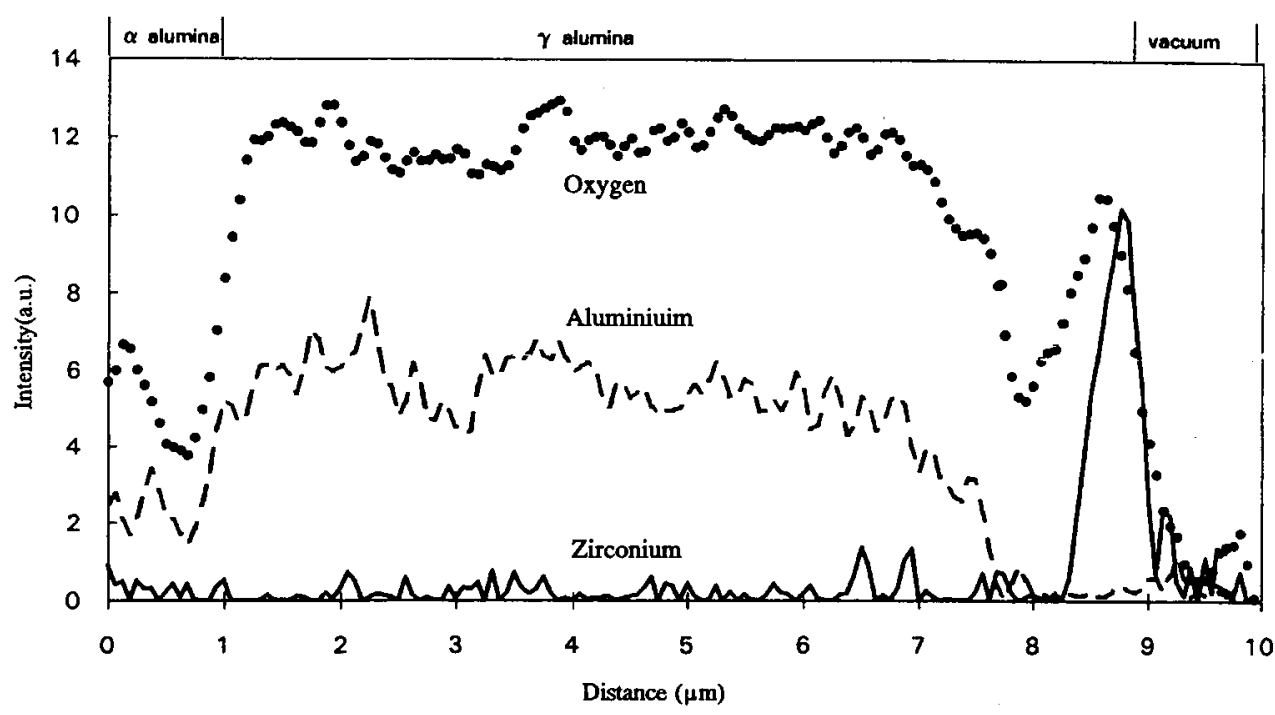

Fig. 5. Deposition profile of YSZ in the type B substrate with 20-min CVD (5 times reduced concentration of the metal chloride vapors) (determined by SAM linescan analysis). 


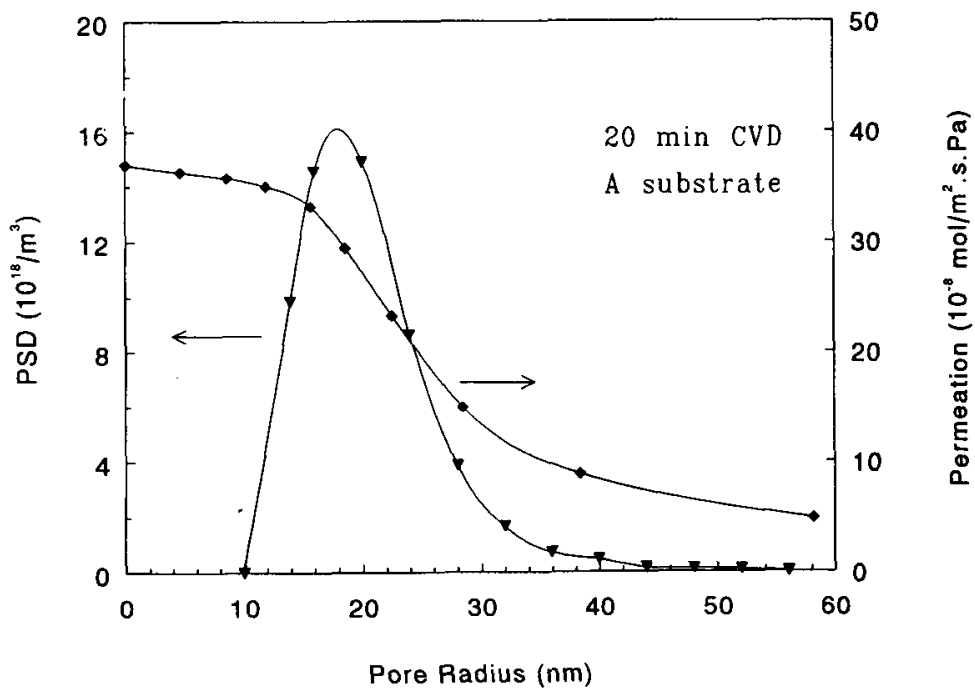

Fig. 6. Accumulative oxygen permeation as a function of pore radius and the pore size distribution (PSD) of active pores in the type A substrate after 20-min CVD (determined by permporometry).

7 shows the size distribution of the active pores of the type B substrates before and after 20-min deposition of YSZ. The average pore radius was reduced from about 9 to $6 \mathrm{~nm}$, while the pore size distribution became broader. In Fig. 7 there is also an indication that there were large pores and/or pinholes in the substrates (a long tail of the accumulative oxygen permeation curve at $r>11 \mathrm{~nm}$ ) before the CVD experiment and they were eliminated (filled by deposition) after the CVD experiment. The elimination of large pores and/or pinholes from the substrate was one of the reasons that the oxygen permeation decreased drastically from $32 \times 10^{-8}$ to $12 \times 10^{-8} \mathrm{~mol} /$ $\left(\mathrm{m}^{2} \cdot \mathrm{s} \cdot \mathrm{Pa}\right)$ after 20 -min deposition. Another reason was the pore narrowing in the top membrane layer. The large decrease of the oxygen permeation after the CVD experiment was also probably due to a small fraction of deposition on the entrance edge of the pores which resulted in an increase of the thickness and thus the resistance to oxygen permeation through the substrate. At this time, it is not possible to separate those different contributions.

When the CVD experimental conditions are changed in such a way that the deposition of YSZ occurs only on top of the substrates (as demonstrated in Fig. 5), there will be no reduction of the average pore size in porous ceramic substrates.
Figure 8 shows the pore size distribution in the type B substrate before and after 20-min deposition of YSZ on the surface toward the metal chloride chamber (with 5 times reduced concentration of metal chlorides). The average pore size remained unchanged after the CVD experiment. However, a decrease of the oxygen diffusional flux through the substrate was observed; for example, the oxygen permeation (at $P_{\mathrm{r}}=0$ ) through the above-mentioned type $B$ substrate decreased from $37 \times 10^{-8}$ to $17 \times 10^{-8} \mathrm{~mol} /\left(\mathrm{m}^{2} \cdot \mathrm{s} \cdot \mathrm{Pa}\right.$ ) (about $50 \%$ reduction) after the CVD experiment. Figure 8 also suggests a smaller number of pores left after deposition of YSZ. This may not be true. One should realize that the pore size distribution presented here is calculated from the oxygen permeation data measured by using permporometry. The calculation was done by assuming that no extra layer would be formed after the CVD experiments. Clearly this is not the case here. The YSZ deposition on top of the substrate in fact formed an extra layer and increased the gas diffusional resistance (through the substrate) due to an increase of the effective thickness of the substrate. Lin et al. ${ }^{8}$ have reported that the average pore size of the porous ceramic substrates was not reduced by depositing solid oxide(s) using (5 times) higher gas fluxes than those given in Table I, while the porosity of the substrates was

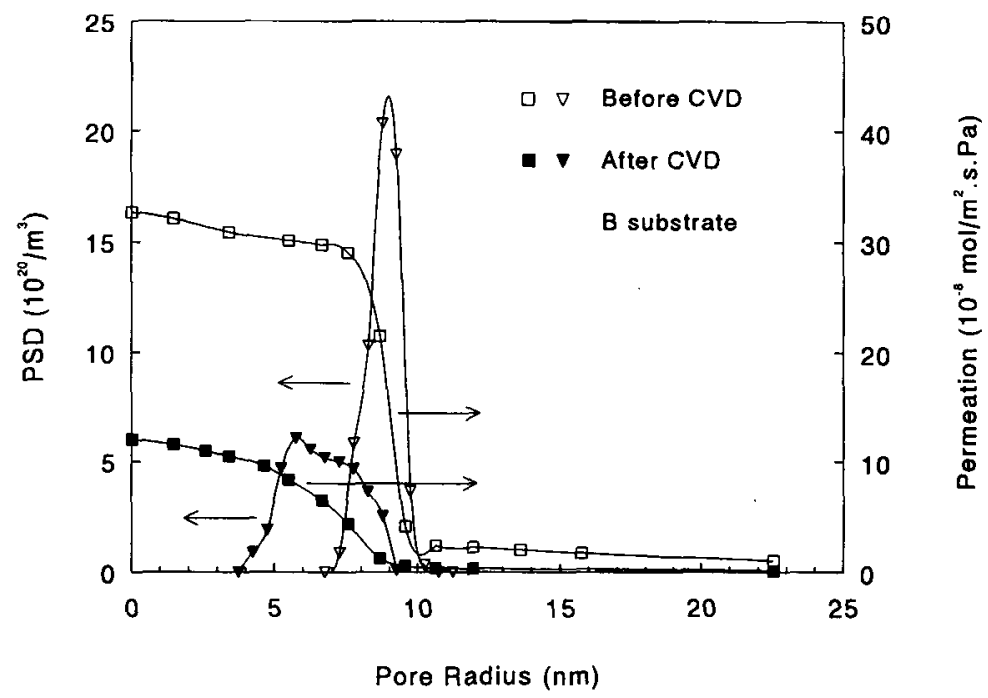

Fig. 7. Accumulative oxygen permeation as a function of pore radius and the pore size distribution (PSD) of active pores in the type B substrate before and after 20-min deposition of YSZ (determined by permporometry). 


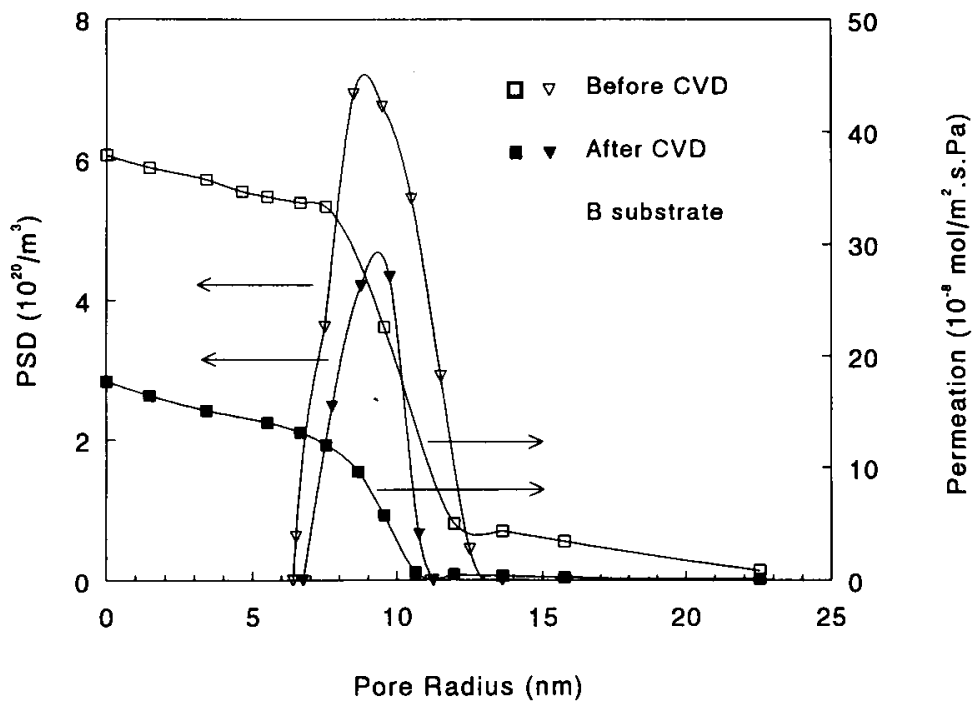

Fig. 8. Accumulative oxygen permeation as a function of pore radius and the pore size distribution (PSD) of active pores in the type B substrate before and after 20-min deposition of YSZ, when an excess amount of water vapor and oxygen gas were supplied (determined by permporometry).

reduced, determined by using the gas permeation methods. This was also probably due to the deposition on top of the substrates, which resulted in a decrease of gas permeation through the CVD modified substrates as described above.

\section{(4) EVD of YSZ}

After all pores have been plugged by depositing YSZ during the CVD stage, the CVD process stops and the EVD process starts, resulting in growth of the YSZ layer toward the metal chloride chamber. The principle is that the oxygen gas and/or water vapor can diffuse to the YSZ plug and be reduced to oxygen ions. These oxygen ions then diffuse through the YSZ plug (compensated by the electron holes or by the opposite migration of electrons) and react with metal chlorides at the surface toward the metal chloride chamber to form YSZ deposition, resulting in growth of the YSZ layer. A gas-tight YSZ layer was formed after (CVD/EVD) deposition of about 50 min (on the type A substrate) and $40 \mathrm{~min}$ (on the type B substrate) by using the experimental conditions described in Table I. The apparent thickness of the YSZ layers was about 1.5 and $0.5 \mu \mathrm{m}$ on the respective type $A$ and type $B$ substrates according to the SEM observation. The thickness of the EVD YSZ layers on both type A and B substrates was not increased in a 2-h EVD experiment by means of SEM observation.

To avoid the formation of a thick YSZ layer, $800^{\circ} \mathrm{C}$ was chosen as the CVD/EVD experimental temperature so that after the pore closure the growth of the YSZ layer proceeded at a very low speed, because a high activation energy is needed for oxygen ions to diffuse through the YSZ layer at such a low temperature (at $800^{\circ} \mathrm{C}$ ). When a higher deposition temperature is used, the EVD process takes place after pore plugging. The thickness of the EVD YSZ layer will increase with the deposition time and consequently thicker YSZ layers can be obtained. A more detailed discussion is given elsewhere. ${ }^{20}$

When the deposition of YSZ does not take place inside the pores, it is very difficult to get pore closure unless a substantially long period of deposition time is used. After a period of deposition of YSZ on top of the substrates, the diffusion resistance for water vapor and oxygen gas increases and the amount of water vapor and oxygen gas diffused through the substrate decreases; thus the concentration ratio of the metal chloride vapors and water vapor/oxygen gas is changed so that the deposition of YSZ is shifted inside the pores. The deposition inside the pores will eventually result in a pore plugging and a dense YSZ layer is formed.

\section{Conclusions}

Deposition of YSZ inside the pores (whether close to the surface toward the metal chloride chamber or not) of porous ceramic substrates will cause pore narrowing and eventually pore closure. After 20-min deposition of YSZ the mean pore radius is reduced from 80 to $20 \mathrm{~nm}$ in the type A substrate and from 9 to $6 \mathrm{~nm}$ in the type B substrate. A gas-tight YSZ layer on porous substrates with a thickness of $0.5-1.5 \mu \mathrm{m}$ is formed after 40-50 min CVD/EVD, depending on the substrates and experimental conditions used. However, a 20 -min deposition of YSZ on top of the type B substrates does not reduce the mean pore size and it is very difficult to get pore closure unless a substantially long period of $\mathrm{CVD} / \mathrm{EVD}$ experiments is conducted.

Deposition profiles depend strongly on the experimental conditions used. The deposition location can be changed from the top to the inside of porous substrates by varying the concentration and/or concentration ratio of the metal/oxygen reactants. The width of YSZ deposition (CVD/EVD experiments at $800^{\circ} \mathrm{C}$ ) is about $5 \mu \mathrm{m}$ when the deposition takes place inside pores with radii ranging from about 10 to $80 \mathrm{~nm}$. The width of YSZ deposition increases with the deposition temperature, e.g., $19 \mu \mathrm{m}$ at $1000^{\circ} \mathrm{C}$, probably because of the Langmuir-Hinshelwood reaction mechanism.

Acknowledgments: Dr. E. G. Keim is acknowledged for his SAM analysis and fruitful discussions, and Prof. dr. H. Verweij for fruitful discussions.

\section{References}

'A. O. Isenberg, "Growth of Refractory Oxide Layers by Electrochemical Vapor Deposition (EVD) at Elevated Temperatures," Proc.-Electrochem. Soc., 77-6, 572-83 (1977)

'L. G. J de Haart, Y. S. Lin, K. J. de Vries, and A. J. Burgeraaf, "Modified CVD of Nanoscale Structures in an EVD of Thin Layers on Porous Ceramic Membranes," J. Eur. Ceram. Soc., 8, 59-70 (1991).

${ }^{3}$ Y. S. Lin, L. G. J. de Haart, K. J. de Vries, and A. J. Burggraaf, "A Kinetic Study of the Electrochemical Vapor Deposition of Solid Electrolyte Films on Porous Substrates,"J. Electrochem. Soc., 137, 3960-66 (1990).

${ }^{4}$ U. P. Pal and S. C. Singhal, "Electrochemical Vapor Deposition of YttriaStabilized Zirconia Films," J. Electrochem. Soc,, 137, 2937-41 (1990).

${ }^{5}$ M. F. Carolan and J. N. Michaels, "Growth Rates and Mechanism of Electrochemical Vapor Deposited Yttria-Stabilized Zirconia Films," Solid State Ionics, 37, 189-95 (1990).

"J.Schoonman, J. P. Dekker, J. W. Broers, and N. J. Kiwiet "Electrochemical Vapor Deposition of Stabilized Zirconia and Interconnection Materials for Solid Oxide Fuel Cells," Solid State Ionics, 46, 299-308 (1991).

'J. P. Dekker, V. E. J. van Dieten, and J. Schoonman, "The Growth of Electrochemical Vapor Deposited YSZ Films," Solid State lonics, 51, 143-45 (1992)

"Y. S. Lin and A. J. Burggraaf, "CVD of Solid Oxides in Porous Substrates for Ceramic Membrane Modification," AIChE J., 38, 445-54 (1992). 
${ }^{4} \mathrm{G}$. R. Gavalas, C. E. Megiris, and S. W. Nam, "Deposition of $\mathrm{H}_{2}$-Permselective $\mathrm{Si}_{2} \mathrm{O}$ Films," Chem. Eng. Sci., 44, 1829-35 (1989).

"Y. S. Lin and A. J. Burggraaf, "Modeling and Analysis of CVD Processes in Porous Media for Ceramic Composite Preparation," Chem. Eng. Sci., 46, 3067-80 (1991).

"F. P. Cuperus, D. Bargeman, and C. A. Smolders, "Permporometry. The Determination of the Size Distribution of Active Pores in UF Membranes," J. Membr. Sci., 71, 57-67 (1992).

${ }^{12} \mathrm{Ch}$. Eyraud, M. Betemps, J. F. Quinson, F. Chatelut, M. Brun, and B. Rasneur, "Détermination de la Répartition des Rayons de Pores d'un Ultrafiltre," Bull. Soc. Chim. Fr., 9-10, I-237-244 (1984).

${ }^{13} \mathrm{~A}$. Mey-Marom and M. Katz, "Measurement of Active Pore Size Distribution of Microsporous Membranes-A New Approach," J. Membr. Sci., 27, 119-30 (1986).

${ }^{14}$ Y. S. Lin and A. J. Burggraaf, "Preparation and Characterization of $\cdot H i g h-$ Temperature Thermally Stable Alumina Composite Membrane,"J. Am. Ceram. Soc., 74, 219-24 (1991).
${ }^{15}$ D. E. Fain, “A Dynamic Flow-Weighted Pore Size Distribution"; pp. 199205 in First International Conference on Inorganic Membranes. Edited by J. Charpin and L. Cot. Montpellier, France, 1989.

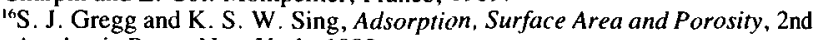
ed. Academic Press, New York, 1982.

${ }^{17}$ G. Z. Cao, J. Meijerink, H. W. Brinkman, and A. J. Burggraaf, "Permporometry Study on the Size Distribution of Active Pores in Porous Ceramic Membranes," J.Membr. Sci., in press.

${ }^{18}$ H. W. Brinkman, G. Z. Cao, J. Meijerink, K. J. de Vries, and A. J. Burggraaf, "Modelling and Analysis of CVD Process for Ceramic Membrane Preparation," Solid State Ionics, in press.

${ }^{19} \mathrm{G}$. Z. Cao, H. W. Brinkman, J. Meijerink, K. J. de Vries, and A. J. Burggraaf, "A Kinetic Study on the Modified CVD Process in Porous Ceramics," submitted to J. Mater. Chem.

${ }^{2 k}$ H. W. Brinkman, G. Z. Cao, J. Meijerink, K. J. de Vries, and A. J. Burggraaf, "Kinetics of the EVD Process for Growing Zirconia/Yttria Films on Porous Alumina Substrates," J. Phys. Colloq., in press. 